Cad.Est.Ling., Campinas, 47(1) e (2):93-98, 2005

\title{
CRIANÇA, CORPO E LINGUAGEM: QUE(M) FALA?
}

\author{
SONIA BORGES \\ (Escola de Psicanálise do Campo Lacaniano, \\ Universidade Veiga de Almeida)
}

\begin{abstract}
RESUMÉ Une convergence peut exister entre les études somatiques ou organiques et la psychanalyse, une fois que ceux-là decrivent les phènomènes et celle-ci donne la raison de sa structure. Cependant, au cas où l'on adopte une position selon laquelle on ne se reconnaît pas la causalité psychique, le sujet de l'inconscient et le critère du transfert, on tombera nécessairement dans une réduction.
\end{abstract}

Para falar da linguagem da criança, começo lembrando uma lenda relatada pelo filósofo americano, John Searle, em que fica bem explicitada a sua posição quanto às noções de sujeito e de representação. O pensamento de Searle, de cunho pragmatista, exerce, hoje, muita influência no campo da Filosofia, da Lingüística, da Psicologia, e em outras áreas do saber.

Mas, vamos à lenda: no livro, A Intencionalidade, Searle faz a construção mítica de uma pequena tribo primitiva em que todos conheciam todos, em que os recém-nascidos eram batizados na presença da tribo inteira, e na qual os indivíduos aprendiam a significação dos nomes pela indicação direta ("Isso é..."); nessa tribo, a linguagem funcionava, então, de maneira absolutamente descritivista, sendo a referência, de cada nome, exclusivamente fixada pelos feixes de descrições aprendidos, um a um, pelo ensinamento de alguém que já seria detentor desse saber. (SEARLE, 1985)

Está claro que Searle não acredita nessa possibilidade, mas defende que esse é o funcionamento primário da linguagem. E, esse sucesso das interações verbais é atribuído ao domínio exercido pelos sujeitos sobre os seus enunciados e à própria qualidade atribuída à linguagem de ser transparente. Nessa perspectiva, fundamentalmente, o significante estaria a serviço do significado, estaria aí para dizermos o que temos em mente, tal como temos a intenção de dizê-lo. Fica, portanto, excluído, qualquer intervalo entre o falar e o querer dizer, de modo que não há lugar para o erro, o deslize, a não ser como acidente no percurso para uma "tomada de consciência" cada vez mais efetiva desse querer dizer, assim como, de como dizer.

Pensar assim implica considerar que contexto, situação, circunstâncias, interações, são imediatamente referenciais ou, em outras palavras, que a linguagem é transparente, 
BORGES - Criança, corpo e linguagem:

auto-explicativa, obedecendo à intencionalidade do sujeito que fala: o saber referencial da língua é concebido como um saber constativo, cognitivo; e o referente, por sua vez, como o que se deixa tocar pela linguagem, sendo, portanto, idêntico a si.

Procede-se, assim à naturalização ou substancialização do contexto, assim como da linguagem, que perde a sua natureza simbólica, equivocidade e ambigüidade. Fica-se no campo do imaginário, ainda que se apele, como bem mostram os trabalhos de Cláudia Lemos, "para as idéias de representação, meta-representações e operações mentais, inflandose a noção da cognição sem se refletir sobre seus fundamentos e limites" (LEMOS, 2000, p. 7). Em consequiência disso, abre-se a possibilidade de também se naturalizar as interações verbais e seus efeitos, seja na clínica ou em quaisquer relações dialógicas.

Mas, por que lanço mão dessa lenda? Porque penso que no cerne das questões sobre a natureza da linguagem, e portanto, de seu tratamento na clínica, neurólogica, fonoaudiológica ou psicanalítica, está nosso modo de conceber as noções de representação e de linguagem. Na tribo imaginada por Searle, ficando desaparecida a distância entre os modos de representação e a realidade a ser apresentada, ou seja, faz-se abstração do caráter simbólico da linguagem, excluindo-se o sujeito em sua singularidade e em seus limites como sujeito do significante, restando o sujeito do significado. Assim sendo, só resta considerar as diferenças na linguagem e as assimetrias nas interações verbais como distúrbios ou déficits atribuídos a patologias orgânicas que, por sua vez, alterariam o funcionamento cognitivo. Na perspectiva da Psicologia, a linguagem é índice do funcionamento cognitivo, mais precisamente, índice das formas adequadas ou patológicas de representação das coisas do mundo de que a linguagem seria instrumento. A visão médica, ou organicista adota, como pressuposto, essa visão da Psicologia, de modo que, para medir a integridade do aparato orgânico e cognitivo, tem como estratégia observar, nos enunciados dos sujeitos, a sua adequação ao que está sendo representado.

Pode-se dizer de maneira breve, que as afasias, as paralisias cerebrais, os distúrbios articulatórios, a surdez e a deficiência mental seriam consideradas como patologias da linguagem determinadas por afecções orgânicas de qualquer tipo. Já os distúrbios de fala, leitura e escrita, a gagueira e os retardos de linguagem, como alterações prioritariamente relacionadas ao mental. O falante é identificado ao seu substrato orgânico e/ou ao seu aparato cognitivo. E, assim sendo, como diz Lier-De-Vitto,

sobre a linguagem parece bastar que se diga que as falas patológicas fogem ao padrão e perturbam a comunicação. Sem querer discutir aqui as idéias de padrão e de comunicação, sabe-se que as ditas falas patológicas são em grande parte interpretáveis e não barram a comunicação. (1998, p. 4)

Fato é que padrão e comunicação sustentam-se sobre o apagamento das diferenças e, portanto, do sujeito na sua historicidade.

Procuro colocar em relação estas posições teóricas, mas, com Freud, considero que a chamada polêmica científica é totalmente estéril. Evitar a polêmica não significa, contudo, negar as controvérsias. Caso se adote uma posição na clínica da fala que abandone a causalidade psíquica, o sujeito do inconsciente e o critério da transferência, necessariamente ocorrerá um reducionismo. Acredito que entre os estudos dos aspectos somáticos ou orgânicos e a psicanálise "pode haver convergência, uma vez que aqueles descrevem os 
Cadernos de Estudos Lingüísticos 47(1) e (2) - Jan./Dez. 2005

fenômenos, e esta dá a razão de sua estrutura [...]" (cf. QUINET, 1999, p. 4). Ou seja, é possível uma clínica que procure ligar uma leitura anatomopatológica dos fenômenos, a uma leitura da história da produção singular de representações e linguagem de um sujeito. Tomemos enunciados de fala e de escrita de crianças em situação de aprendizagem ou de tratamento:

"Eu comemorei a páscoa na casa do meu vo, mas, não ganhei avo de páscoa"

(BORGES et al., 2001)

"Bota a mãozinha prá frente,

Bota a mãezinha do lado,

Bota a mãozinha prá trás."

(FARIA, 1997)

"E iogurte, não pode comê iogurte antes das refeições? E porta, não pode comê porta antes das refeições?"

(LEMOS, 2000)

Seria possível interpretar os dois primeiros enunciados, de escrita, recorrendo-se à categoria de erro? Ou, poderíamos dizer que tais erros devem ser atribuídos a alguma dificuldade de representar a fala? E quanto ao último, de fala, poder-se-ia invocar a necessidade de relação biunívoca entre enunciado e referente, para descrevê-lo?

Fica patente que essa produção coloca em questão a mencionada relação entre linguagem e intencionalidade. Entre esses enunciados e o referente não há nem oposição simples, nem identidade, pois fazem parte daquilo a que se referem. A natureza jocosa dos enunciados das crianças nasce justamente desse encontro. Pode-se dizer que o seu caráter referencial só ocorre a partir do tropeço e da falha. O referente não se apresentou, portanto, como idêntico a si mesmo, como uma substância preexistente na mente da criança, a que ela faria corresponder uma representação de que a linguagem seria veículo.

Para quê, então, apontam os enunciados que vimos? Antes de mais nada, para a noção de sujeito, com sua história e singularidade. Portanto, para a noção de enunciação, como sempre em excesso em relação ao enunciado. Apontam, portanto, para uma outra relação entre sujeito e de linguagem. Mas, de que sujeito, então, está-se falando? Como considerar seus enunciados e interações verbais?

Desde a Psicopatologia da Vida Cotidiana (1901) Freud estabeleceu o caráter de realização implicado no que comumente designamos como tropeço, falha, erro ou deslize. Mencionou esses fenômenos como algo da ordem da substituição por desvio, inversão ou omissão, constituindo, pois, uma mensagem a ser decifrada, que testemunha um desejo inconsciente.

Se tomarmos o pensamento de Lacan:

o que caracteriza, ao nível da distinção significante/significado, a relação do significante ao que está lá como terceiro indispensável, a saber, o referente, é propriamente que o significante o trai. (LACAN, 1975, p. 55) 
BORGES - Criança, corpo e linguagem:

É imaginário o ideal de transparência da linguagem e, conseqüentemente, de metacognição ou metalinguagem, quer se trate de relações em que a patologia está em questão, ou não. Para a Psicanálise, "o estado do sujeito (neurose ou psicose) depende do que se desenrola no Outro [...]", como diz Lacan (1998, p. 555). Nesta passagem, Lacan considera a própria constituição subjetiva, dizendo que a existência se articula para o sujeito como uma pergunta sobre o que é, no campo do Outro: homem ou mulher, vivo ou morto... o que o Outro quer de mim? Em seu retorno a Freud, evidencia a primazia do significante na constituição do sujeito:

\footnotetext{
desde antes do seu nascimento, o sujeito já está aí situado, não apenas como emissor, mas, como átomo de um discurso concreto. Ele se acha dentro dessa linha de dança deste discurso, ele é se quiserem, ele mesmo esse discurso. Escreveram-lhe uma mensagem na cabeça, e ele se acha situado inteiramente na sucessão das mensagens, cada uma das suas escolhas é uma fala.(1954, p. 135)
}

Os enunciados que mostrei são escritos numa outra gramática, submetida às regras da pulsão, do desejo. Do Outro, enquanto "tesouro dos significantes", lhes vêm os seus elementos constitutivos. Sob "avo", está "ovo" e "avô", sob "mãezinha do lado", "mãezinha" $e$ "mãosinha". Vê-se aí a constituição dos enunciados da criança, que obedece às leis da metáfora e da metonímia. A presença do Outro, "tesouro de significantes", conforme Lacan, fica patente mesmo nos momentos mais iniciais da aquisição da fala e também da escrita.

Trata-se, então, de outra gramática? Se Lacan afirma que "é toda estrutura da linguagem que a experiência psicanalítica descobre no inconsciente" (LACAN,1998, p. 498), isso se dá na medida em que o inconsciente é o que dizemos (id., p. 844). Para ler Freud, Lacan recorre à Ciência da Lingüística, particularmente a Saussure e a Jakobson. Na esteira do pensamento de Saussure sobre o "valor do signo" e das "leis da linguagem" - a metáfora e a metonímia - enunciadas por Jakobson, pensa a relação inconsciente e linguagem. Freud já transformara em paradigma a composição dos sonhos, segundo as leis da condensação e do deslocamento, para a interpretação das "formações do inconsciente" de um modo geral. Com essas leis, Freud situa a interpretação psicanalítica no campo do deciframento. Deciframento, porque tais formações são tecidas entre a insistência dos imperativos pulsionais, e as exigências de defesa do eu, ou seja, são produções orientadas pela lógica do desejo, de modo que estão impedidas as suas inscrições no campo da consciência. Tais imperativos eróticos não podem se manter no campo de visibilidade da consciência, a menos que se apresentem sob uma forma disfarçada, como na escrita dos sonhos, nos lapsos ou equivocações de linguagem, como vimos.

Nesta perspectiva, os signos, longe de estarem a serviço de uma intencionalidade, são marcados pela polissemia, pela ambigüidade, sendo as associações do falante, sujeito dividido, as responsáveis pela circunscrição do horizonte semântico de tais signos Conseqüentemente, com a Psicanálise, há uma abertura quase infinita da tessitura significativa da linguagem. Os enunciados, assim como o sonho, têm uma marca de singularidade em cada sujeito. Qualquer fixidez na economia semântica dos signos é recusada. Pode-se dizer que o conceito de linguagem e, portanto, de sentido, formulado por Freud, tal como relido por Lacan, rompeu decisivamente com a idéia de relação direta, 
Cadernos de Estudos Lingüísticos 47(1) e (2) - Jan./Dez. 2005

biunívoca, entre signo e referente, já que estão fundados no inconsciente e a sua matériaprima, são os desejos. $\mathrm{O}$ ato de falar é sempre substituição de alguma coisa, pois o que sustenta os enunciados é o objeto $\boldsymbol{a}$, causa de desejo. Por isso, a escrita do inconsciente implica uma outra gramática, uma outra semântica, diz respeito à alíngua - à língua materna - , ordenada de forma distinta daquela que supostamente se constituiria sob o registro do eu e da consciência.

Freud denominou de "destinos das pulsões" as inscrições das forças pulsionais no campo da representação. O movimento das pulsões, como força, passou a ser inaugural no ser, o sentido não sendo articulado imediatamente, mas, como um momento secundário, tecido pelo princípio do prazer, que regula a ordenação das pulsões. A falta que constitui o objeto das pulsões é a mesma que constitui o núcleo real do inconsciente. Por isso o isomorfismo entre inconsciente e gozo, ou a inseparabilidade do corpo e da linguagem. E, é exatamente em torno desse núcleo real da falta que o inconsciente se estrutura, no simbólico, como uma linguagem.

Contudo, o sentido só pode começar a se ordenar por meio da oferta de objetos de satisfação prodigalizados pelo Outro, ficando patente a existência de um intervalo insuperável entre os registros da força pulsional e da representação. Por quê? "Porque o Outro falta. A inscrição da falta no Outro, que Freud chamou de castração, o faz inconsistente e faltoso, sem garantias, o Outro não existe. O sujeito, como falta - a - ser, não encontra o que lhe falta no Outro" (QUINET, 2001, p. 4).

Mas, Lacan fala também do Outro como objeto $\boldsymbol{a}$, o Outro do desejo, que constitui a causa do desejo. É o objeto que vem, na fantasia, responder à pergunta do desejo: 'Que quero?' "O Outro é reduzido a esse objeto em torno do qual a pulsão faz a volta e que se encontra no quadro da fantasia que o sujeito projeta no telão do Outro" (id., p. 5) Efeito da linguagem, o objeto a é parte integrante da fantasia através da qual se aprende a se representar a realidade.

Enfim, é a dimensão do Grande Outro que falta a Searle. Por isso, não percebe que o único conteúdo intencional que existe na utilização da linguagem, ou mais propriamente de um nome, é o de se referir àquilo que os outros se referem ao utilizar esse nome. Essa é a função normal da linguagem. "Mesa" se refere a "mesa" porque à mesa se chama mesa, e não por uma necessidade interna e imanente de sua significação.

Vejamos outro enunciado de criança. Ao fazer prova de seleção para uma escola, a professora lhe dita a palavra "Pindamonhongaba", e a criança escreve:

$$
\text { "Min - da - mi - nha - goia - ba" }
$$

E, o que dizer do adolescente seminarista que descobre sua equivocação na escuta do que rezava diariamente: em lugar de "Senhor, eu não sou digno de que entreis em minha morada", dizia:

"Senhor, eu não sou digno de três namoradas..."

O objeto é desde sempre objeto do desejo, objeto fantasiado, ainda que reconhecer isso não resolva a questão da contingência radical de sua nomeação. $\mathrm{O}$ aspecto decisivo é 
BORGES - Criança, corpo e linguagem:

o da não-coincidência da rede simbólica e do circuito da realidade simbolizada por essa rede: de ambos os lados há uma sobra. A simbolização da realidade, a inscrição do circuito da realidade na rede significante, abre no real o vazio do não-simbolizável; por outro lado, a simbolização acarreta necessariamente um excesso da própria rede significante.

As crianças estão em seus princípios constitutivos próximas da estrutura que nos ordena, elas denunciam o tempo todo o quanto são faladas, ditas pelo imperativo linguageiro dos grandes. Parecem meros intermediários, porta-vozes de uma mensagem da qual não sabem o remetente e o destinatário.

\section{$\overline{\text { REFERÊNCIAS BIBLIOGRÁFICAS }}$}

FARIA, N. (1997). Nas letras das canções, a relação oralidade-escrita. Maceió: Editora Universitária, UFPE.

FELMAN, S. (1980). Le scandale du corps parlant. Paris: Seuil.

FREUD, S. (1984). Psicopatologia da vida cotidiana (1901). In: Obras completas de Sigmund Freud. $2^{\text {a }}$ ed. Buenos Aires: Amorrortu.

GUATIMOSIN, B. (2000). O vingar do sujeito. Texto inédito.

LACAN, J. (1954-55/1985). O Seminário, livro 2: O eu na teoria de Freud e na técnica da psicanálise. Rio de Janeiro: Jorge Zahar Editor.

. (1955-56/1985). O Seminário, livro 3: As psicoses. Rio de Janeiro: Jorge Zahar Editor. . (1957/1998). A instância da letra no inconsciente ou a razão desde Freud. In: Escritos. Rio de Janeiro: Jorge Zahar Editor. . (1966). Posição do inconsciente In: Escritos. Op.cit . (1975/1982). O Seminário, Livro 20: Mais ainda. Rio de Janeiro: Jorge Zahar Editor.

LEMOS, C. (2000). O erro como desafio empírico a abordagens cognitivistas do uso da linguagem: ocaso da aquisição da linguagem. Texto inédito.

LIER-DE-VITTO, F. (1998). A teoria como ideologia na abordagem dos fatos desviantes da linguagem. Texto inédito

QUINET, A. (2001). A heteridade de Lacan. Inédito. . (2001). Psicanálise e psiquiatria. Rio de Janeiro: Marca d’Água Livraria e Editora.

SEARLE, J.R. (1985). L'Intentionalité. Paris: Seuil. 